\title{
Coupling of living polystyryllithium anions and living polyethyl vinyl ether cations
}

\section{S. Creutz, C. Vandooren, R. Jérôme*, and P. Teyssié}

Center for Education and Research on Macromolecules (CERM), University of Liège,

Sart-Tilman, B6, B-4000 Liège, Belgium

\section{Summary}

Living polystyryllithium anions and living polyethyl vinyl ether cations have been successfully coupled. Indeed, no residue of any of the two original homopolymers is observed in the final product, when they are used in a stoichiometric amount. This method has been exploited in order to synthesize $A B$ and $A B A$ polyethyl vinyl ether (PEVE) (A) / polystyrene (PSt) (B) block copolymers with a high efficiency.

\section{Introduction}

Discovery of the living anionic polymerization by szwarc in 1956 (1) has resulted in a tremendous research effort aiming at the molecular tailoring of polymeric materials. In contrast, the molecular design of polymers by a living cationic mechanism has been next to impossible for a long time. However, the pioneering works of Higashimura et al. (2) and kennedy et al. (3) have recently opened remarkable routes to the carbocationic macromolecular engineering. For instance, vinyl ethers can be polymerized by a combination of a protonic acid ( $\mathrm{HB}$ ) and a Lewis acid $\left(\mathrm{MX}_{\mathrm{n}}\right)$. The actual initiator is the adduct of the vinyl ether and the protonic acid (equation 1), the C-B linkage of which is activated by the Lewis acid.

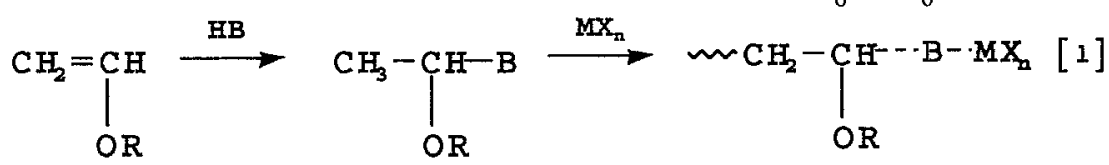

Higashimura et al. (2) have convincingly demonstrated the possible tailoring of polyalkyl vinyl ethers by cationic polymerization initiated with the $\mathrm{HI} / \mathrm{ZnI}_{2}$ pair. One of the advantages of this living polymerization is the straightforward synthesis of end-functional polyvinyl ethers by reaction of the cationic active centers with a nucleophilic agent, such as an alcohol and the anion of diethylmalonate (4) . A polymeric nucleophile might also be used as illustrated by the coupling reaction of cationically polymerized living poly(THF) and living anionic polystyrene (5). To the best knowledge of these authors,

\footnotetext{
${ }^{*}$ Corresponding author
} 
only two research groups have reported so far on the successful coupling reaction of a living polyvinyl ether with a macromolecular species. Riffle et al. have quenched living polybutylvinyl ether with living poly(methylmethacrylate) as prepared by GTP (6). Kleuskens et a1. have used a low molecular weight poly (ethylene glycol) as a quencher for living polyvinyl ether chains (7) . However, this coupling reaction leads to the formation of an acetal bond between the two blocks, which is known to be unstable under acidic conditions.

This paper will emphasize how efficient the coupling of living polyethyl vinyl ether cations and living polystyrene anions can be ( equation 2). Indeed, $A B$ and $A B A$ polyethyI vinyl ether (A) / polystyrene (B) block copolymers have been prepared with a high efficiency, as supported by molecular weight and composition close to the expected values and a very narrow molecular weight distribution.

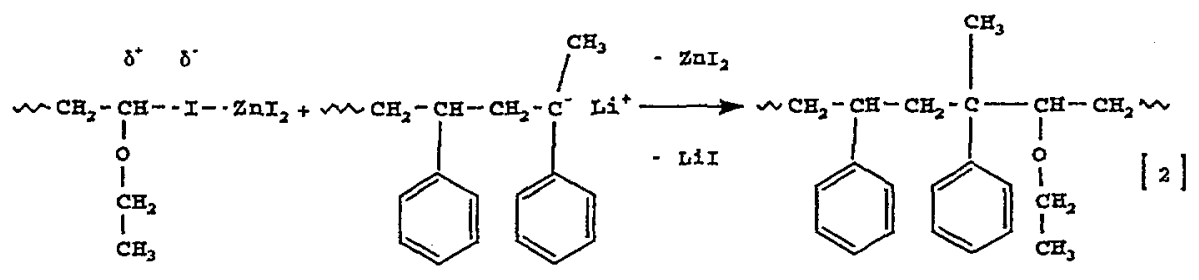

\section{Experimental}

A $57 \% \mathrm{HI}$ aqueous solution (Aldrich) was dried over $\mathrm{P}_{2} \mathrm{O}_{5}$ (Merck). Hydrogen iodide was then dissolved in dry $n$.hexane and the solution was stored in the dark at $-18^{\circ} \mathrm{C}$ under ary nitrogen. The HI concentration was determined by extracting the acid with deionized water and titrating the aqueous layer with a standard $\mathrm{NaOH}$ solution (8).

A known amount of zinc iodide (Aldrich) was dried overnight under vacuum in the dark and dissolved in a known volume of dry diethyl ether. The solution was kept in the dark at $-18^{\circ} \mathrm{C}$ under dry nitrogen until use (9).

N.hexane, toluene and ethyl vinyl ether (Merck) were dried over calcium hydride and distilled before use. Diethyl ether was dried over sodium prior to distillation. THF was purified by refluxing over a freshly prepared sodium-benzophenone complex. All chemicals were analytical reagent grade or equivalent.

styrene and $\alpha$-Methylstyrene were first vacuum distilled from calcium hydride and then stored under a nitrogen atmosphere at $-20^{\circ} \mathrm{C}$. The required amount of styrene was first added with the same volume of dry toluene and a few drops of $\alpha$ Methylstyrene. This solution was dropwise added with fluorenyllithium until a persistent orange color was observed and it was finally distilled under reduced pressure just prior to polymerization.

Polymerization was carried out under dry nitrogen in balloons equipped with three-way stopcocks. All glassware was flamed under vacuum before use. Solutions were transferred with 
stainless steel capillaries or with glass syringes through a rubber septum.

Ethyl Vinyl Ether Polymerization : The desired amount of HI was added to a dry solution of ethyl vinyl ether in toluene (48 weight/volume) previously cooled down to $-30^{\circ} \mathrm{C}$. It was allowed to react for 15 minutes. Zinc iodide was then added $\left([\mathrm{HI}]_{0} /\left[\mathrm{ZnI}_{2}\right]_{0}=10\right)$ and the polymerization was allowed to proceed until the nearly complete conversion of the monomer. An aliquot of this living polyethyl vinyl ether solution was withdrawn and quenched with methanol for characterization of the polyethyl vinyi ether.

Styrene polvmerization : One drop of $\alpha$-Methylstyrene was added to the requested volume of THF (5\% weight polymer / volume THF ), which was then cooled down to $-78^{\circ} \mathrm{C}$. The solvent was dropwise added with sec.Buti until a persistent red color was observed and the required amount of this initiator was then added, followed by a dilute styrene solution in toluene. The typical orange color of the polystyryl anion first appeared and was rapidly replaced by the deep red color characteristic of the $\alpha$-Methylstyryl anion. Difunctional polystyrene was polymerized in the same way by using naphthalenyllithium as a difunctional initiator.

Coupling reaction : Solution of polystyryllithium at $-78^{\circ} \mathrm{C}$ was quickly transferred to the polyethyl vinyl ether solution, by using a stainless steel capillary. Discoloration of the polyanion occurred instantaneously. The addition was stopped as soon as a slightly persistent coloration was observed. The final solution was quenched ten minutes later with degassed methanol.

Characterization: Size exclusion chromatography (SEC) was carried out in THF at $45^{\circ} \mathrm{C}$ using a Hewlett-Packard 1090 liquid chromatograph equipped with four PLGel Columns ( 100, 500, 10000 and 100000 A ) , a Hewlett-Packard 1037A Refractive Index Detector and a UV diode array detector. Polystyrene standards were used for calibration. ${ }^{{ }^{1}} \mathrm{H}$ and ${ }^{13} \mathrm{C}$ IMR spectra were recorded at 400 and $100 \mathrm{MHz}$, respectively, with a Brüker AN 400 super conducting magnet equipment.

\section{Results and discussion}

The living polymerization of ethyl vinyl ether has been initiated with $\mathrm{HI} / \mathrm{ZnI}_{2}$ at $-30^{\circ} \mathrm{C}$ in toluene, as reported by Higashimura et a1.(10). Molecular weight of the polyethyl vinyl ether at complete monomer conversion is expectediy in a good agreement with the theoretical value based on the monomer to initiator molar ratio.

Styrene polymerization has been initiated in THF at $-78^{\circ} \mathrm{C}$ with sec-butyllithium. In order to improve the observation of the endpoint addition of polystyryllithium to the living polyvinyl ether solution (persistent coloration) , the living polystyrene chains have been endcapped with a few $\alpha$ Methylstyrene units, the anion of which is more easily detected due to a deep red coloration compared to a light orange one for the styryllithium anion. It is the reason why styrene has been 

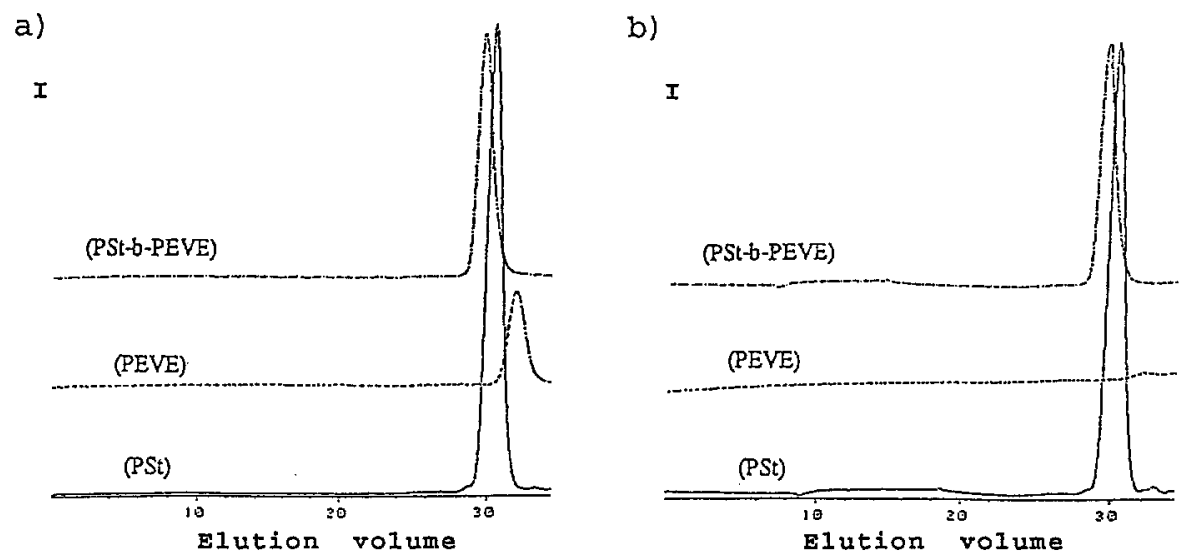

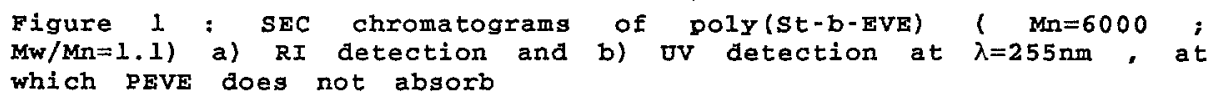

added with a few percents of $\alpha$-Methylstyrene units before initiation. Styrene is first polymerized and then endcapped with $\alpha$-Methylstyrene (11).

Thus living polystyrene, at $-78^{\circ} \mathrm{C}$, is added to living polyvinyl ether, cooled down to $-30^{\circ} \mathrm{C}$, until a slight coloration is permanently observed. The amount of the added living polystyrene is very close to the previously calculated stoichiometric amount. The final product is recovered by the complete removal of the solvent and analyzed by SEC without any further purification, so that the extent of the coupling reaction can be estimated from the SEC traces of the individual polymeric components and the crude reaction product. Two diblock copolymers have successfully been symthesized (Table I). As shown in figure 1 , the presence of any of the two original homopolymers cannot be detected by SEC, whatever the detection technique, i.e. refractive index (R.I.) or UV at $255 \mathrm{~nm}$. ${ }^{1} \mathrm{H}$ and ${ }^{13} \mathrm{C}$ NMR confirms the expected composition, which proves that the endpoint addition of polystyryllithium to polyethyl vinyl ether allows the reaction stoichiometry to be reached very closely ( Figs. 2 and 3 ). Molecular weight of the polyethyl vinyl ether block has been first approximated by SEC (polystyrene calibration, and then calculated by ${ }_{1} \mathrm{H}$ NMR spectroscopy. In this respect, the intensity of the acetal proton of the polyethyl vinyl ether end-group, that originates from the quantitative quenching of the living chains with methanol ( $\left.-\mathrm{CH}-\left(\mathrm{O}-\mathrm{CH}_{2}-\mathrm{CH}_{3}\right)-\mathrm{O}-\mathrm{CH}_{3}: 4.6 \mathrm{ppm}\right)$ has been compared to the intensity of the protons of the repeat unit $(-\mathrm{CH}-(-\mathrm{O}-$ $\left.\mathrm{CH}_{2}-\mathrm{CH}_{3}\right)$ - : $\left.3.3-3.8 \mathrm{ppm}\right)$. There is a good agreement between the two methods, although SEC overestimates the polyethyl vinyl ether molecular weight. 
Table I

\begin{tabular}{|c|c|c|c|c|c|c|c|c|c|}
\hline & \multicolumn{2}{|c|}{ PSt } & \multicolumn{3}{|c|}{ PEVE } & \multicolumn{4}{|c|}{ Copolymer } \\
\hline & $\begin{array}{c}\mathrm{Mn} \\
\text { (SEC) }\end{array}$ & $\begin{array}{c}\text { Molocular } \\
\text { weight } \\
\text { distribution }\end{array}$ & (SEC) & (NMR) & $\begin{array}{l}\text { Molecular } \\
\text { weight } \\
\text { distribution }\end{array}$ & $\begin{array}{c}\mathrm{Mn} \\
\text { (SEC) }\end{array}$ & $\begin{array}{l}\text { Molecular } \\
\text { weight } \\
\text { distribution }\end{array}$ & $\begin{array}{c}\text { Theor etical } \\
\text { composition } \\
* \\
\text { PSt-PEVE }\end{array}$ & $\begin{array}{c}\text { Observed } \\
\text { composition } \\
\text { 'H NMR } \\
\text { (ut \%) }\end{array}$ \\
\hline (PSt-b-PEVE) & 4500 & 1.1 & 2000 & 1700 & 1.1 & 6000 & 1.1 & $73-27$ & $76-24$ \\
\hline (PSt-b-PEVE) & 8500 & 1.05 & 2000 & 1700 & 1.1 & 10500 & 1.05 & $83-17$ & $82-18$ \\
\hline (PEVE-b-PSt-b-PEVE) & 5000 & 1.1 & 2500 & 2100 & 1.05 & 10000 & 1.1 & $55-45$ & $60 \cdot 40$ \\
\hline
\end{tabular}

$* \%(\mathrm{PSt})=\left(\mathrm{Mn}_{\operatorname{SEC}}(\mathrm{PSt}) /\left(\left(\mathrm{Mn}_{\mathrm{SEC}}(\mathrm{PSt})+\mathrm{Mn}_{\mathrm{NMR}}(\mathrm{PEVE})\right)\right) * 100\right.$
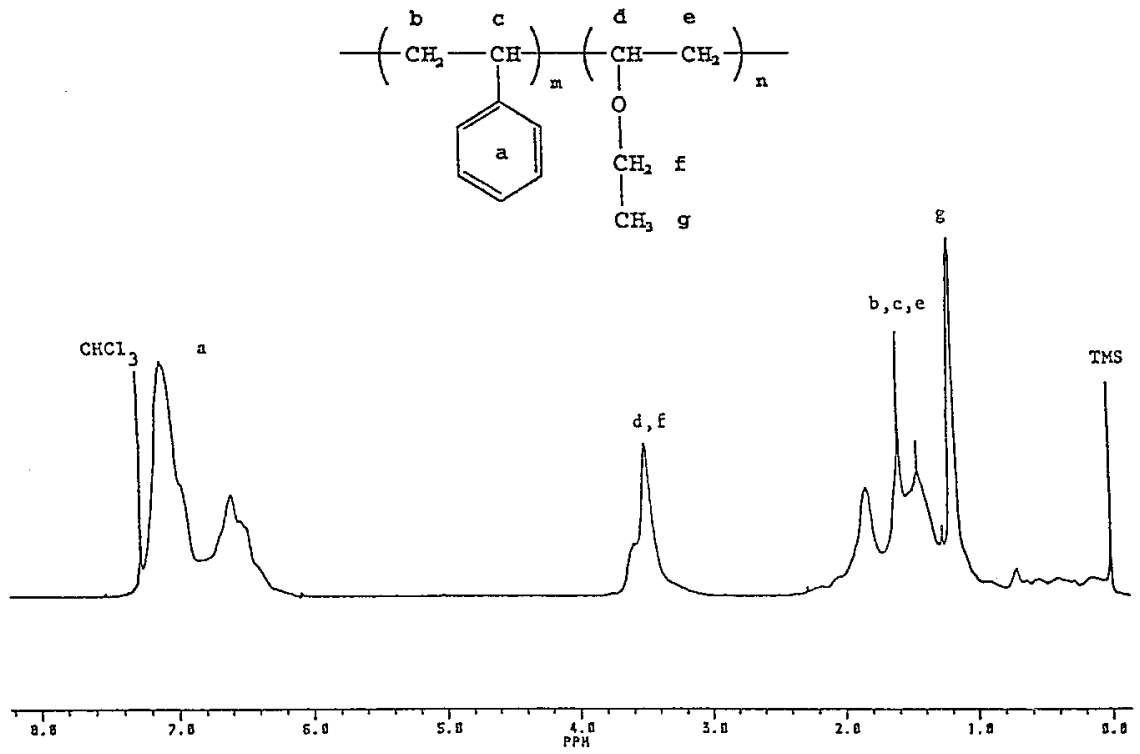

Figure 2: $1_{H}$ NMR spectrum (400MHz) of poly (St-b-EVE) $(\mathrm{Mn}=6000 ; \mathrm{MW} / \mathrm{Mn}=1.1)$

Since formation of a diblock copolymer by coupling living polystyryl anions and living polyethyl vinyl ether cations has proved to be highly efficient within the limits of the sensitivity of SEC and NMR, synthesis of a triblock copolymer has been considered, in which an inner polystyrene block is covalently bonded to polyethyl vinyl ether outer sequences. 


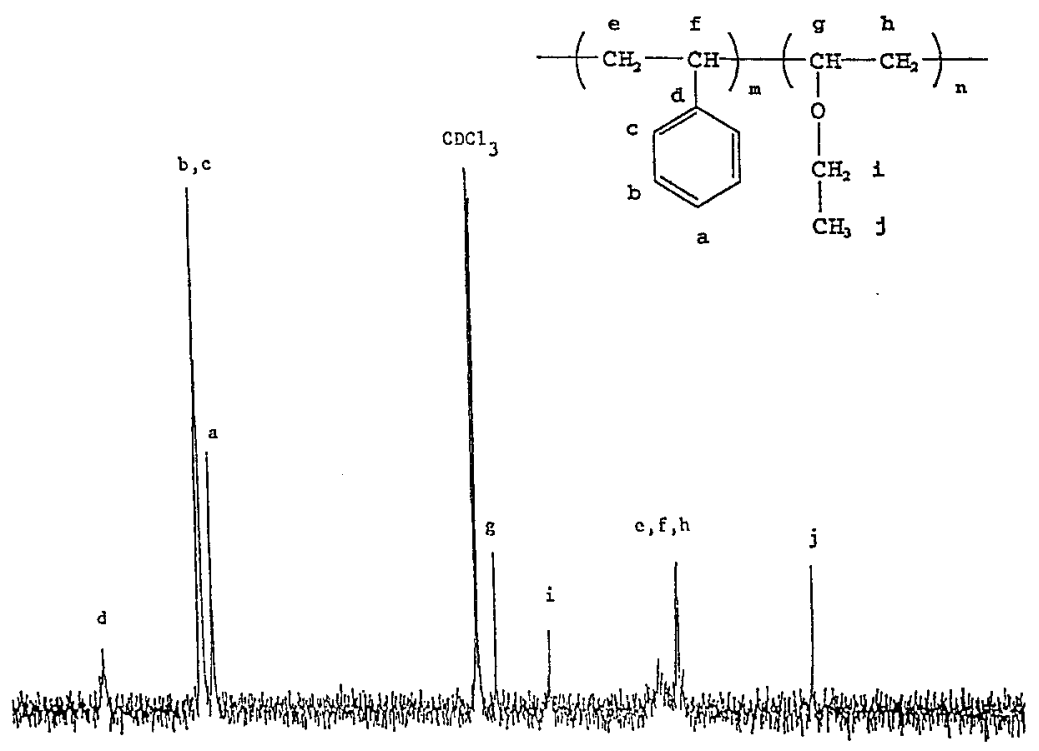

ta

Figure $3:{ }^{13} \mathrm{C}$ NMR spectrum $(100 \mathrm{MHz})$ of poly (St-b-EVE) ( $M \mathrm{Mn}^{2}=6000 ; \mathrm{MW} / \mathrm{Mn}=1.1$ )

Living difunctional polystyrene chains have been added to a solution of living monofunctional polyethyl vinyl ether chains as reported for the synthesis of diblocks. In order to avoid the possible contamination of the final product by some undesirable diblock, the separation of which would be quite a problem, polystyrene has been used in a smaller amount - by ca. 108 - than requested by the coupling reaction stoichiometry. The triblock copolymer appears to be formed quantitatively with respect to polystyrene. The size exclusion chromatogram of the crude reaction product (figure $4 \mathrm{a}$ ) indeed shows some unreacted polyethyl vinyl ether, although the presence of homopolystyrene and a possible diblock cannot be detected. The excess of polyethyl vinyl ether can be easily removed by the selective precipitation of the copolymer in methanol, i.e. a selective solvent of polyethyl vinyl ether. Figures $4 \mathrm{~b}$ and $4 \mathrm{c}$ show that the pure triblock is then recovered.

\section{Conclusion}

Since coupling of living polyethyl vinyl ether cations and living polystyrene anions can be carried out in a highly efficient way, the interest in this block copolymerization technique might be renewed. Indeed, coupling of cationically and anionically polymerized living chains is a potential route to well-defined block copolymers, that has been rapidly disregarded mostly due to a limited efficiency. The herein reported method might be extended to living polyanions that can 
be endcapped with $\alpha$-Methylstyrene, e.g. polyanions derived from isoprene, butadiene, styrene derivatives and $\alpha$-Methylstyrene itself (1I) . Various poly(alkyl vinyl ethers) and poly (fluorinated vinyl ethers) might be part of diblocks of a valuable surface or interfacial activity. They could also participate to the building up to triblock copolymers that have potential as new thermoplastic elastomers.

a)

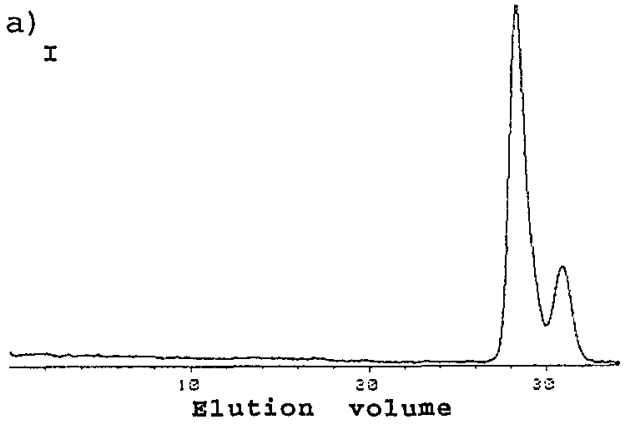

Figures 4 : SEC chromatograms of poly (EVE-b-St-b-EVE) ( $\mathrm{M}=10000$; $\mathrm{Mw} / \mathrm{Mn}=1.1$ )

a) crude product before precipitation. After precipitation : b) RI detection and c) UV detection at $\lambda=255 \mathrm{~nm}$, at which PEVE does not absorb b)

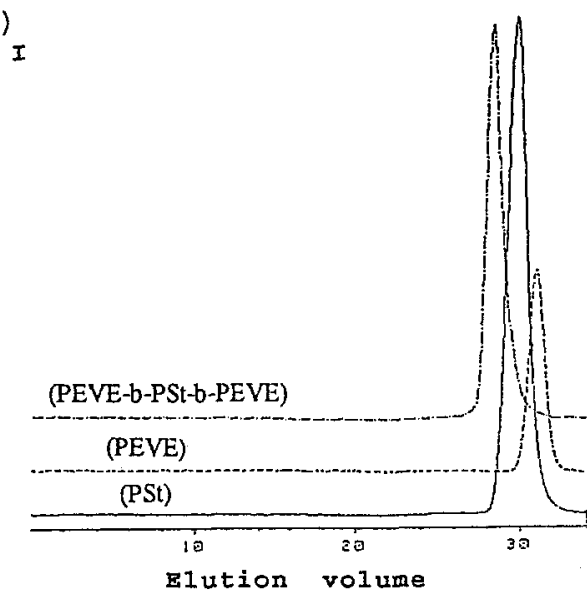

c)

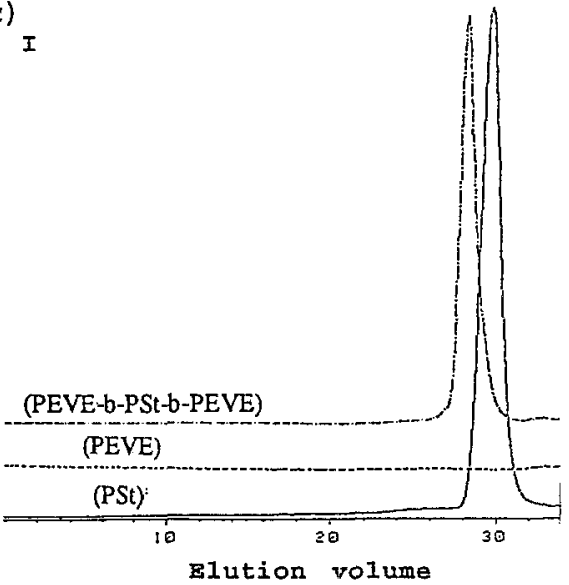

\section{Acknow ledgements}

The authors are grateful to the " Institut pour l'Encouragement de la Recherche Scientifique dans l'Industrie et l'Agriculture "for a fellowship to one of them (C.V.) . They are also grateful to the " Service de la programmation de la politique Scientifique " for general support in the frame of the "pole d'attraction Interuniversitaire : Polymères" . 


\section{References}

1 a) Szwarc,M. ,Levy, M. ,Milkovich, R., J. Amer. Chem. Soc.,78, 2656, (1956); b) Szwarc, M. , Nature, 178, 1168, (1956)

2 Sawamoto,M.,Prog. Polym. Sci.,16,111, (1991)

3 Ivan, B. and Kennedy,J.P., " Designed Polymers by Carbocationic Macromolecular Engineering:Theory and Practice ",Hanser, Munich (1991)

4 As a recent review see:Ivan, B. and Kennedy,J.P., Ind.J.Techno1., $31,183,(1993)$

5 Richards,D.H. , Kingston, S.B.and Soue1, T. , Polymer, 12, 68, (1978)

6 Verma, A. ,Nielsen, A. ,McGrath, J.E.and Riffle,J.S., Polymer Bulle$\operatorname{tin}, 23,563,(1990)$

7 Loontjens, T., Derks, F. and Kleuskens, E, Polymer Bulletin, 27, 519, (1992)

8 Miyamoto,M. , Sawamoto,M. and Higashimuxa, T., Macromolecules, 17, $265,(1984)$

9 Sawamoto,M. , Okamoto, C. and Higashimura, T., Macromolecules, 20. 2693, (1987)

10 Kojima, K., Sawamoto,M. and Higashimura,T., Macromolecules, 22. $1552,(1989)$

11 Teyssié.. Ph., Jérôme, R., Ouhadi,T. and Fayt,R. , U.S. Patent $4,461,874,(1984)$

Accepted March 16, 1994

C 